\title{
Overweight/obesity and associated cardiovascular risk factors in sub-Saharan African children and adolescents: a scoping review
}

Simeon-Pierre Choukem ${ }^{1,2,3^{*}}$, Joel Noutakdie Tochie ${ }^{2,4^{*}} \mathbb{D}$, Aurelie T. Sibetcheu ${ }^{2,5}$, Jobert Richie Nansseu ${ }^{2,6}$ and Julian P. Hamilton-Shield ${ }^{7}$

\begin{abstract}
Introduction: Recently, childhood and adolescence overweight/obesity has increased disproportionately in developing countries, with estimates predicting a parallel increase in future cardiovascular disease (CVD) burden identifiable in childhood and adolescence. Identifying cardiovascular risk factors (CVRF) associated with childhood and adolescence overweight/obesity is pivotal in tailoring preventive interventions for CVD. Whilst this has been examined extensively in high-income countries, there is scant consistent or representative data from sub-Saharan Africa (SSA).
\end{abstract}

Objective: This scoping review synthesises contemporary studies on CVRF associated with overweight and obesity in SSA children and adolescents to provide evidence on the current burden of overweight/obesity and CVD in this population.

Methods: We searched MEDLINE and Google Scholar up to July 31, 2019 for observational and experimental studies and systematic reviews addressing childhood and adolescence overweight/obesity and CVRF in SSA without language restriction. Four investigators working in four pairs, independently selected and extracted the relevant data. The methodological quality of all included studies was assessed.

Results: We included 88 studies with a total of 86,637children and adolescents from 20 SSA countries. The risk of bias was low in 62 (70.5\%), moderate 18 (20.5\%), and high in eight (9\%) studies. Overweight/obesity in SSA children and adolescents is rising at an alarming rate. Its main associations include physical inactivity, unhealthy diets, high socio-economic status, gender and high maternal body mass index. Identified CVRF in overweight/obese SSA children and adolescents are mainly metabolic syndrome, hypertension, dyslipidaemia, diabetes and glucose intolerance. There is a dearth of guidelines or consensus on the management of either childhood overweight/ obesity or CVRF in overweight/obese SSA children and adolescents.

Conclusion: The current findings suggest an urgent need to review current health policies in SSA countries. Health education and transforming the current obesogenic environment of the SSA child and adolescent into one which promotes physical activity and healthy dietary habits is required.

Keywords: Obesity, Overweight, Children, Adolescent, Cardiovascular risk factor, Sub-Saharan Africa

\footnotetext{
*Correspondence: simeon.choukem@univ-dschang.org;

joeltochie@gmail.com

${ }^{1}$ Department of Clinical Sciences, Faculty of Medicine and Pharmaceutical

Sciences, University of Dschang, Dschang, Cameroon

${ }^{2}$ Health and Human Development (2HD) Research Network, Douala,

Cameroon

Full list of author information is available at the end of the article
}

(c) The Author(s). 2020 Open Access This article is distributed under the terms of the Creative Commons Attribution 4.0 International License (http://creativecommons.org/licenses/by/4.0/), which permits unrestricted use, distribution, and reproduction in any medium, provided you give appropriate credit to the original author(s) and the source, provide a link to the Creative Commons license, and indicate if changes were made. The Creative Commons Public Domain Dedication waiver (http://creativecommons.org/publicdomain/zero/1.0/) applies to the data made available in this article, unless otherwise stated. 


\section{Background}

Sub-Saharan African (SSA) is one of the poorest regions in the world, with a double public health burden of communicable diseases (malaria, HIV/AIDS, and tuberculosis) and a rising incidence of non-communicable diseases (NCD), especially cardiovascular disease (CVD) [1]. Overweight/obesity is an emerging problem, stemming from increasing urbanisation and westernised lifestyles [2], which in turn has led to the emergence of a nutrition transition characterised by a shift to a higher calorie diet [3]. In this resource-poor setting, the trend in overweight/obesity may likely increase as excess weight is often considered to reflect health, prestige, and prosperity whilst the lean are perceived to be unhealthy or financially poor [4-6].

Likewise, childhood and adolescence overweight/ obesity is one of the major global public health problems of the twenty-first century [7, 8]. Globally, the prevalence of overweight and obesity rose by $47.1 \%$ in children over the last three decades [7]. Almost $6.7 \%$ or 43 million (35 million in developing countries) under-five children were either overweight or obese in 2010, with 92 million at risk of overweight [9]. The global prevalence is expected to reach $9.1 \%$ or 60 million in 2020 [9]. Furthermore, the prevalence of overweight and obesity in children and adolescents in developing countries increased from 8.1 to $12.9 \%$ in boys and 8.4 to $13.4 \%$ in girls over thirty years [7], demonstrating the time trend in this developing epidemic.

The ill-health of childhood and adolescence overweight/obesity is particularly worrisome due to the potential for long-term sequelae in adulthood [10]. Un-addressed, contemporary evidence suggests that overweight/obesity in childhood and adolescence is predictive of an increased risk of adult obesity, cardiovascular, metabolic, psychological complications, some malignancies, and premature death in adulthood [11-14]. Childhood and adolescence associates with hypertension, atherogenic dyslipidaemia, metabolic syndrome, early and accelerated atherosclerosis, type 2 diabetes mellitus and obstructive sleep apnoea [1519]. Although investigating CVD risk factors among children and adolescents is crucial because childhood or adolescence is a critical temporal window for the development of obesity in adulthood [20], these risk factors have been less well examined in overweight/ obese SSA children and adolescents. This review critically synthesises the current burden of childhood and adolescence overweight/obesity and associated cardiovascular risk factors, as well as contemporary diagnostic and therapeutic options in SSA. This should inform policy-makers on the various public health interventions necessary to mitigate cardiovascular risk in this vulnerable overweight/obese population at these earlier stages.

\section{Methods}

We searched two main electronic databases: MEDLINE (via Pubmed) and Google Scholar from inception to July 31, 2019 for observational, interventional studies and systematic reviews addressing childhood and adolescence overweight/obesity and cardiovascular risk factors in SSA without language restriction. A comprehensive search strategy was conducted using the key words: "overweight", "obesity", "children", "adolescent”, "prevalence”, "cardiovascular risk factor", "diagnosis", "management", cross-referenced with subSaharan Africa or the names of sub-Saharan Africa countries to obtain the maximum possible number of studies (Table 1). The reference lists of retrieved articles were scanned in order to identify any additional relevant study. Eligible articles and documents were scrutinised based on adequate sample size and robust study design to extract data on the prevalence of childhood and adolescence overweight/obesity, associated cardiovascular risk factors, diagnostic methods and treatment strategies in sub-Saharan Africa. One

Table 1 Search strategy for MEDLINE and adaptability to Google scholar data base

\begin{tabular}{ll}
\hline Region/Country & sub Saharan Africa OR sub Saharan African OR subSaharan Africa OR Angola OR Benin OR Botswana OR Burkina Faso OR \\
& Burundi OR Cameroon OR Cape Verde OR Central African Republic OR Chad OR Comoros OR Congo OR Democratic \\
& Republic of Congo OR Djibouti OR Equatorial Guinea OR Eritrea OR Ethiopia OR Gabon OR Gambia OR Ghana OR Guinea \\
& OR Guinea-Bissau OR Ivory Coast OR Kenya OR Lesotho OR Liberia OR Madagascar OR Malawi OR Mali OR Mauritania OR \\
& Mauritius OR Mozambique OR Namibia OR Niger OR Nigeria ORPrincipe OR Reunion OR Rwanda OR Sao Tome OR Senegal \\
& OR Seychelles OR Sierra Leone OR Somalia OR South Africa OR Sudan OR Swaziland OR Tanzania OR Togo OR Uganda \\
& ORWestern Sahara OR Zambia OR Zimbabwe OR Central Africa OR Central African OR West Africa OR West African OR Western \\
& Africa OR Western African OR East Africa OR East African OR Eastern Africa OR Eastern African OR South African OR Southern \\
& Africa OR Southern African.
\end{tabular}

Disease/Risk factor Cardiovascular risk factor OR hypertension OR high blood pressure OR elevated blood pressure OR salt intake OR diabetes OR artherosclerosis OR glucose intolerance OR dyslipidemia OR cholesterol OR triglyceride OR smoking OR tobacco OR alcohol consumption OR physical inactivity OR lack of exercise OR diet OR nutrition OR urbanization OR socio-economic status OR lack of sleep OR sleep apnoea.

Participants $\quad$ Children OR child OR childhood OR infants OR toddlers OR adolescents OR adolescence OR obesity OR obese OR overweightOR nutritional status OR fat OR fatness OR adiposity OR fatty OR body size 
pair of investigators (SPC and JNT) independently screened records by abstract and title. Subsequently, two pairs of investigators (SPC, JNT, ATS and JRN) independently screened possibly relevant full texts for articles directly reporting the definition, prevalence, management of overweight/obesity in SSA as well as CVRF associated with overweight and obesity in SSA children and adolescents. We only included peerreviewed cross-sectional, case-control, cohort studies, randomized controlled trials and systematic reviews recruiting at least 30 SSA children and adolescents residing in SSA. We excluded letters to the editor, modeling studies, qualitative studies, and conference proceedings. Studies reporting overweight/obesity linked to corticosteroids, eating disorders, family hypercholesterolemia, antipsychosis medication were excluded. Missing data was sought by contacting the corresponding author of the research article via emails. When the corresponding author could not be contacted, the article was excluded. Discrepancies between two pairs of investigators (SPC, JNT, ATS and JRN) were solved through discussion and consensus. A standardized and pre-tested data extraction form was used by two pairs of investigators (SPC, JNT, ATS and JRN) to independently extract bibliometric information (the name of first author), study characteristics (country and sample size), participants' age range, diagnostic criteria for overweight/obesity, prevalence of overweight, obesity and combined overweight/obesity. Data from each country was reported separately for multinational studies. Study quality for observational, randomized controlled trials and systematic reviews was assessed using the methods described by Hoy et al. [21], the SPIRIT 2013 Statement tool [22] and the AMSTAR 2 tool [23] respectively. Finally, using data retrieved from a myriad of epidemiological studies, interventional studies and systematic reviews, the ensuing findings present a narrative synthesis of the most up-to-date and key literature regarding childhood and adolescence overweight/obesity and cardiovascular risk factors in SSA (Fig. 1).

\section{Results and discussion}

Selection: We included 88 studies with a total of 86,637 children and adolescents from 20 SSA countries. The risk of bias was low in $62(70.5 \%)$, moderate in 18 (20.5\%), and high in eight (9\%) studies.

\section{Clinical assessment and diagnostic criteria}

The assessment of childhood and adolescence overweight/obesity has been a subject of debate in SSA due to the absence of universal consensus [24]. Although fat mass and body mass index (BMI) among children and adolescents are often positively correlated $[25,26]$, the assessment of childhood and adolescence overweight/obesity using BMI may be flawed by several draw backs: BMI does not discriminate between lean and fat mass; BMI varies sharply with respect to growth, gender, and ethnicity [27, 28]; BMI alone is argued to have high specificity but low sensitivity to detect excess adiposity [29]. As a result, international cut-offs [30-33] using percentiles and standard deviations from a median reference point are preferred (Table 2) to traditional BMI cut-off values of $\geq 30 \mathrm{~kg} / \mathrm{m} 2$ and $\geq 25 \mathrm{~kg} / \mathrm{m} 2$ for obesity and overweight, respectively. The dual use of the International Obesity Task Force (IOTF) and WHO cutoffs is recommended for the assessment of the prevalence of childhood and adolescence overweight [34].

In a recent systematic review of 283 articles investigating overweight/obesity transition in SSA school-aged children, international cut-offs were reported in 82 articles $(29 \%)$ as the scale used to stratify body weights into underweight, normal-weight, overweight and obesity [24]. Meanwhile, $48.8 \%$ of included studies cited the mean BMI, BMI-z-score, weight z-scores, body fat percentage, waist circumference, skin fold measures, and/or weight and height measures as the diagnostic tools for childhood and adolescence overweight/obesity [24]. The high heterogeneity of the types of measurements altered the comparability of studies, and regional time trends analyses. Thus, there is a need for a universal consensus towards scales such as WHO cut-points which have the merit of being more sensitive to identify overweight/ obese male and female children irrespective of the age groups [35].

\section{Prevalence and trends of overweight and obesity in SSA Prevalence in preschool children (under-five years)}

Evidence from a recent meta-analysis of demographic and health surveys from 26 SSA countries suggest that 10.7 million or $6.8 \%$ of under-five children were overweight or obese between 2010 and 2014 [36]. Countries with alarming prevalence levels of childhood and adolescence overweight/obesity included Sierra Leone (16.9\%), Cameroon (15.9\%) and Malawi (14.5\%), while much lower prevalence was observed in Ethiopia (3.0\%), Togo (2.6\%) and Senegal (2.0\%) [36]. On the other hand, there is a parallel increase in the burden of stunting in Africa, a proof of the on-going dual burden of over- and undernutrition in the continent [37].

\section{Prevalence in school-aged children and adolescents}

There is a high heterogeneity in studies reporting prevalence levels of overweight/obesity in school-aged children in SSA due to the large socio-cultural differences, the rapidity of the epidemiologic transition and 


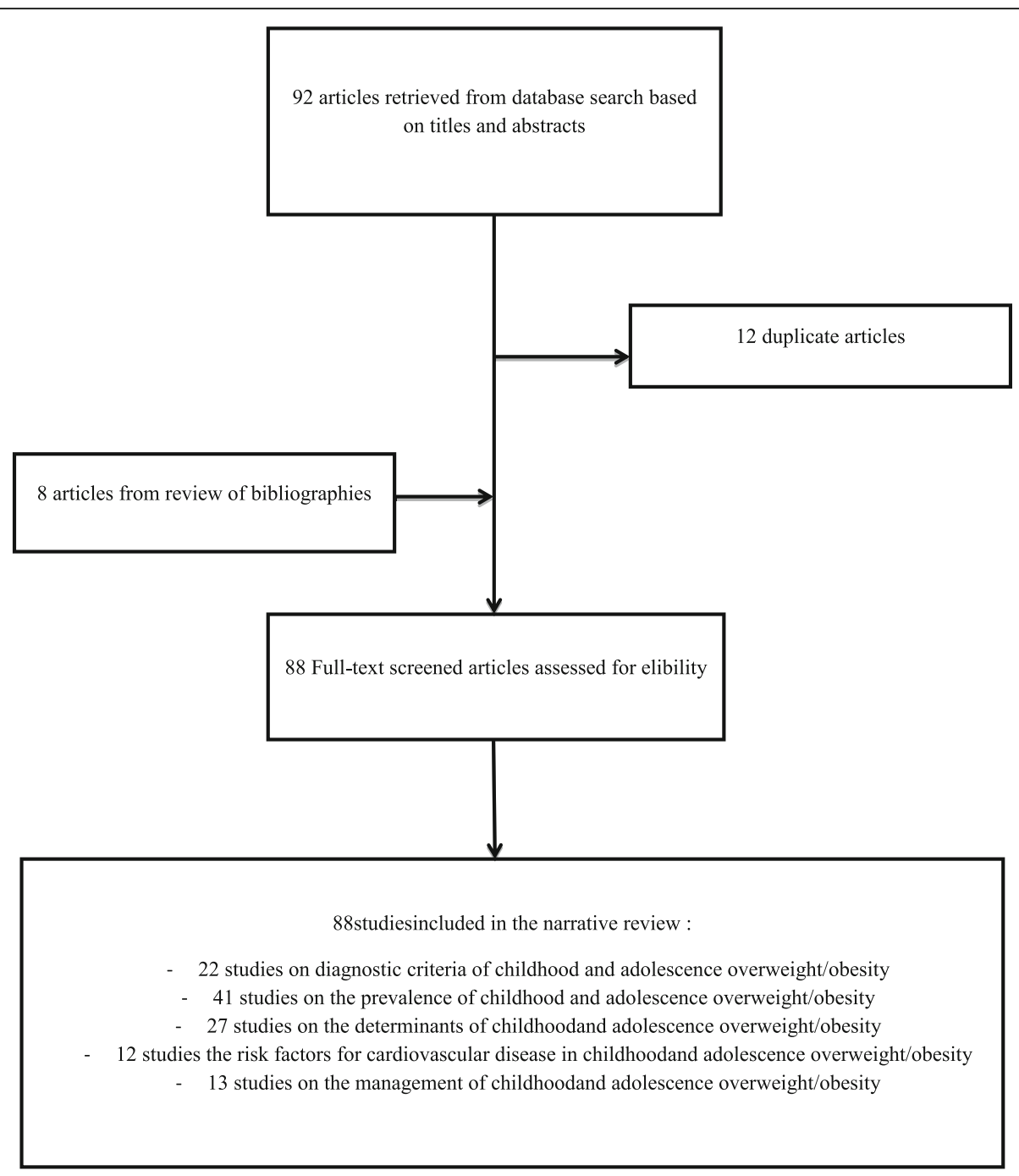

Fig. 1 Flow diagram of study selection

methodological differences between studies [24]. As of the year 2013, results from a meta-analysis based on SSA countries showed that prevalence of overweight and obesity in SSA school-aged children (5-17 years) was 10.6 and $2.5 \%$, respectively [24]. More representative national data on the prevalence of childhood overweight/obesity in SSA [38-73] is illustrated in Table 3. Although these prevalence levels are high, they are lower than trends in childhood and adolescence obesity in high-income settings. For instance, the prevalence of overweight and obesity in the

Table 2 International cut-off values for childhood overweight and obesity

\begin{tabular}{|c|c|c|}
\hline International cut-offs & Age group & Cut-off \\
\hline \multirow[t]{2}{*}{ WHO growth standard $[27,28]$} & $<5$ year & $\begin{array}{l}\text { Overweight: }+2 S \mathrm{SD} \leq \mathrm{BMI}<+3 \mathrm{SD} \\
\text { Obesity: } \mathrm{BMI} \geq+3 \mathrm{SD}\end{array}$ \\
\hline & 5-19years old & $\begin{array}{l}\text { Overweight: }+1 \mathrm{SD}<\mathrm{BMI}<+2 \mathrm{SD} \\
\text { Obesity: } \mathrm{BMI}>+2 \mathrm{SD}\end{array}$ \\
\hline Centre for Diseases Control [29] & 2-19years old & $\begin{array}{l}\text { Overweight }=85 \text { th }-94 \text { th BMI percentiles } \\
\text { Obesity }>95 \text { th BMI percentiles }\end{array}$ \\
\hline International Obesity Task Force [30] & $2-18$ years old & $\begin{array}{l}\text { Overweight percentile curve passing though } \\
\mathrm{BMI}=25 \mathrm{~kg} / \mathrm{m} 2 \text { at age } 18 ; \\
\text { Obesity percentile curve passing through } \\
\mathrm{BMI}=30 \mathrm{~kg} / \mathrm{m} 2 \text { at age } 18\end{array}$ \\
\hline
\end{tabular}


Table 3 Prevalence of overweight/obesity in school-aged children for different sub-Saharan African Countries

\begin{tabular}{|c|c|c|c|c|c|c|c|c|}
\hline \multirow{2}{*}{$\begin{array}{l}\text { Survey } \\
\text { year }\end{array}$} & \multirow[t]{2}{*}{ Investigators } & \multirow{2}{*}{$\begin{array}{l}\text { Sub-Saharan } \\
\text { African Country }\end{array}$} & \multirow{2}{*}{$\begin{array}{l}\text { Sample } \\
\text { Size }\end{array}$} & \multirow{2}{*}{$\begin{array}{l}\text { Participants' } \\
\text { Ages (years) }\end{array}$} & \multirow{2}{*}{ Diagnostic criteria } & \multicolumn{3}{|c|}{ Prevalence rates (\%) } \\
\hline & & & & & & Overweight & Obesity & $\begin{array}{l}\text { Combined } \\
\text { overweight/obesity }\end{array}$ \\
\hline 2009 & Manyanga T et al [39] & Benin & 2681 & $13-17$ & WHO & 11.2 & 0.6 & 11.8 \\
\hline 2008-2009 & Dabone C et al [40] & Burkina Faso & 649 & $7-14$ & WHO & N/A & N/A & 2.3 \\
\hline 2010 & Koueta F et al [41] & Burkina Faso & 435 & $13-25$ & IOTF & N/A & $\mathrm{N} / \mathrm{A}$ & 8.6 \\
\hline 2013 & Choukem SP et al [42] & Cameroon & 1343 & $3-13$ & WHO & 9.6 & 2.9 & 12.5 \\
\hline 2007 & Manyanga T et al [39] & Djibouti & 1711 & $13-17$ & WHO & 18.8 & 5.2 & 24 \\
\hline 2012 & Teshome T et al [43] & Ethiopia & 559 & $10-19$ & WHO and TSFT & $11-12.9$ & $2.7-3.8$ & N/A \\
\hline 2013 & Alemu E et al [44] & Ethiopia & 800 & $15-19$ & CDC & 8.6 & 0.8 & 9.4 \\
\hline 2014 & Askal T et al [45] & Ethiopia & 845 & $9-14$ & CDC & 8 & 1.8 & 9.8 \\
\hline 2014 & Gebremichael B et al [46] & Ethiopia & 463 & $10-18$ & CDC & 9.9 & 2.8 & 12.7 \\
\hline 2014 & Shegaze M et al [47] & Ethiopia & 456 & $13-19$ & WHO & 9.7 & 4.2 & 13.9 \\
\hline 2016 & Desalew A et al [48] & Ethiopia & 448 & $11-15$ & CDC & 14.7 & 5.8 & 20.5 \\
\hline 2006 & Manyanga T et al [39] & Ghana & 6156 & $13-17$ & WHO & 8.7 & 1.0 & 9.7 \\
\hline 2008 & Kyallo F et al [49] & Ghana & 344 & $9-14$ & WHO & N/A & N/A & 19 \\
\hline 2010 & Morge $\mathrm{V}$ et al [50] & Ghana & 218 & $5-14$ & WHO & $\mathrm{N} / \mathrm{A}$ & $\mathrm{N} / \mathrm{A}$ & 17.4 \\
\hline 2010 & Kumah DB et al [51] & Ghana & 500 & $10-20$ & IOTF & 12.2 & 0.8 & 13 \\
\hline 2012 & Mohammed $\mathrm{H}$ et al [52] & Ghana & 270 & $5-15$ & WHO & 15.8 & 10.9 & 26.7 \\
\hline 2010 & Kramoh KE et al [53] & Ivory Coast & 2038 & $6-18$ & BMI & 4 & 5 & 9 \\
\hline 2011 & Kamau JW et al [54] & Kenya & 5325 & $10-15$ & BMI & 8.7 & 3.1 & 11.8 \\
\hline 2010 & Van den Berg VL [55] & Lesotho & 221 & 16 & WHO, CDC and IOTF & $10.4-15.4$ & $1.8-4.1$ & $14.5-19$ \\
\hline 2009 & Manyanga T et al [39] & Malawi & 2305 & $13-17$ & WHO & 10 & 0.8 & 10.8 \\
\hline 2014 & Oumar $\mathrm{H}$ et al [56] & Mali & 984 & $5-19$ & WHO and IOTF & $2.6-5.12^{`}$ & $0.3-1.8$ & N/A \\
\hline 2010 & Manyanga T et al [39] & Mauritania & 2028 & $13-17$ & WHO & 24.3 & 3.4 & 27.7 \\
\hline 2006 & Caleyachetty R et al. [57] & Mauritius & 841 & $9-10$ & IOTF & 17.4 & 4.9 & 22.3 \\
\hline 1983-2013 & Ejike CECC [58] & Nigeria & 21842 & $3-20$ & $\begin{array}{l}\text { WHO, IOTF, TSFT } \\
\text { and BMI }\end{array}$ & $5-12$ & $0-5.8$ & N/A \\
\hline 2015 & Adam VY et al [59] & Nigeria & 195 & $6-12$ & $\mathrm{WHO}$ & 7.7 & 3.1 & 10.8 \\
\hline 2011 & Faye J et al [60] & Senegal & 2356 & $11-17$ & N/A & N/A & 9.34 & N/A \\
\hline 1999 & Stettler N et al [61] & Seychelles & 5514 & $4-17$ & IOTF & 12.6 & 3.8 & 16.4 \\
\hline 2001-2004 & Armstrong MEG et al [62] & South Africa & 10,195 & $6-13$ & CDC & 15.8 & 3.9 & 19.7 \\
\hline 2010 & Toriola AL et al [63] & South Africa & 1172 & $10-16$ & CDC & 10.1 & 4.9 & 15 \\
\hline 2011 & Tathiah N et al [64] & South Africa & 963 & $9-12$ & CDC & 9 & 3.8 & 12.8 \\
\hline 2013 & Pienaar AE [65] & South Africa & 547 & $6-9$ & CDC & 9.4 & 7.3 & 16.7 \\
\hline 2007 & Aisha AMB et al [66] & Sudan & 80 & $5-13$ & CDC & 18.75 & 18.75 & 37.5 \\
\hline 2011 & Nagwa MA et al [67] & Sudan & 1138 & $10-18$ & WHO & 10.8 & 9.7 & 20.5 \\
\hline 2011 & Salman Z et al [68] & Sudan & 304 & $6-12$ & CDC & 14.8 & 10.5 & 25.3 \\
\hline 2015 & El Raghi HA et al [69] & Sudan & 290 & $10-18$ & $\mathrm{BMI}$ & 26.2 & 28.3 & 54.5 \\
\hline 2012 & Pangani IN et al [70] & Tanzania & 1781 & $8-13$ & WHO & 15.9 & 6.7 & 22.6 \\
\hline 2015 & Kimario JT [71] & Tanzania & 140 & $10-12$ & IOTF, TSFT & N/A & N/A & $20-24.3$ \\
\hline 2014 & Chebet M et al [72] & Uganda & 958 & $8-12$ & $\mathrm{BMI}$ & 32.3 & 21.7 & 54 \\
\hline 2013 & Nsibambi CAN [73] & Uganda & 1929 & $6-9$ & $\mathrm{WHO}$ and $\mathrm{CDC}$ & 7 & 4 & 11 \\
\hline 2011 & Peltzer K et al [74] & Uganda and Ghana & 5613 & $13-15$ & BMI & 6.19 & 0.71 & 6.9 \\
\hline
\end{tabular}

${ }^{*}$ Total sample size of narrative review of 42 studies conducted in Nigeria. BMl: Body mass index; CDC: Centres for Disease Control and Prevention; IOTF: International Obesity Task Force; N/A: Not available data; TSFT: Triceps skinfold thickness; UN: United Nations; WHO: World Health Organisation 
USA is 33 and $18 \%$, respectively [74]. Similarly, over the past 25 years, the prevalence of overweight/obesity has doubled (14 to $29 \%$ ), while the obesity rate has tripled (3 to $9 \%$ ) in both Canadian children and adolescents $[35,75]$.

\section{Factors associated with overweight/obesity and cardiovascular diseases in sub-Saharan African children and adolescents}

Several risk factors in obese/overweight SSA children and adolescents have been recognised to contribute to the development of CVD. These include determinants of childhood and adolescence obese/overweight on the one hand and risk factors for the development of CVD among overweight/obese children and adolescents on the other hand.

\section{Determinants of childhood and adolescence overweight/ obesity in sub-Saharan African children and adolescents}

Gender and age The sex distribution of obesity in SSA has a predilection for the female gender. In SSA, on average, $7.6 \%$ of boys and $15.4 \%$ of girls aged 5-17 years are overweight/obese, while the prevalence of obesity in boys and girls aged $5-17$ years is 2.0 and $3.9 \%$, respectively [24]. The reverse is true for the under-fives as supported by findings of a meta-analysis which identified that boys are 1.15-fold more likely to be overweight/ obese compared to girls in SSA [36]. Higher trends of overweight/obesity in SSA girls may be explained by differences in gender roles especially those necessitating strenuous physical activity more among boys than girls [76], and social/cultural desirability whereby being overweight/obese is an admired trait for girls [5].

Physical inactivity The rise in the prevalence of childhood and adolescence overweight/obesity has also been linked with an increase in childhood and adolescence sedentary behaviours, mainly due to indoor activities such as computer games, television viewing, and the internet [42, 45, 47, 77, 78]. In Ghana, a cross-sectional study among senior high school students aged 15 to 19 years, showed a significant association between physical inactivity and overweight [76]. More recently, a similar trend was observed in a younger cohort (3-13 years) of 1343 Cameroonians demonstrating a positive association between overweight/obese status and regular utilisation of passive means of travel to school or not doing sport at school [41]. Similarly, a recent Ethiopian crosssectional study reported that physical activity conveyed protection (adjusted odds ratio [AOR]: 0.21, 95\% confident interval [95\% CI]: 0.08-0.57) against child and adolescent overweight/obesity while children who spent $\geq 3 \mathrm{~h}$ per day sitting, increased their odds for overweight/ obesity by 3.5 [46]. A composite of factors contribute to physical inactivity of overweight/obese children in lowincome settings like SSA: urbanisation of cities with resultant lack of open playgrounds in schools and communities, the increase in criminal acts which render neighbourhoods unsafe for outdoor activities, and the persistent emphasis on academic excellence at the expense of physical activity of children [79].

Unhealthy diet Regular consumption of an unhealthy diet is a major precursor for obesity, metabolic syndrome, type 2 diabetes and coronary artery disease. Developing countries, including those in SSA, are not immune to this risk considering the shift from consumption of traditional low-energy density to high-calorie westernized foods $[45,80]$. This type of diet is rich in refined carbohydrates, saturated fat and sweetened carbonated beverages, with low levels of polyunsaturated fatty acids and fibres [39, 41]. More interestingly, the consumption of sweet foods [40, 42, 45-47], skipping breakfast [45], eating more than three regular meals per day [46] and eating two snacks per day [45], have been identified as independent determinants of childhood and adolescence overweight/obesity in SSA as in other parts of the World. Children and adolescents are particularly exposed because of the sale of 'fast foods' in school cafeteria [81]. Aggressive advertisement by multinational companies and lack of public awareness of the health effects these high-energy foods contribute to obesity risk in children [82]. Furthermore, prolonged television/computer viewing hours decreases the time allocated to physical activity whilst favouring the passive consumption of junk foods and sweetened beverages. In addition, children and adolescents in particular are exposed to advertisements of these unhealthy foods in the media [83]. In the Birth-to-twenty cohort conducted in South Africa, eating patterns of participants aged 13 and 17 years were evaluated and revealed that consumption of snacks while watching screens was common and significantly increased with age [83]. In South African school premises, $85 \%$ of adolescents purchase food and $62 \%$ are unhealthy like candies, crisps, cold drink, fried chips, and white bread [83].

Socio-economic status (SES) In developed countries, high SES is inversely related to child and adolescent adiposity [79]. However, the reverse is true in low- and middle-income countries [40, 42, 64, 84]. We found two systematic reviews pointing to a positive association between overweight/obesity and SSA children of higher SES $[24,85]$, probably due to increased sedentary behaviours and increased accessibility to packaged foods high in sugars and saturated fats, more affordable to families with of higher SES or living in urban settings. Recently, a Cameroonian study investigating the association 
between childhood overweight/obesity and SES found that children from high SES families were two-fold more likely to be overweight/obesity than children from families with low SES [41]. Interestingly, the risk of overweight/obesity for children of high SES persisted after adjusting for potential confounders like age, gender, early life factors (birth weight and type of feeding till six months of age), parental factors (maternal age, BMI, alcohol consumption, maternal and paternal education level) and current child factors (number of meals per day, consumption of fruits and sweet drinks, physical activity at school and leisure time, travel means to school, television and electronic use habits, sleeping habits and pocket money) [41].

Urban versus rural residence Several studies, including systematic reviews, have clearly shown that childhood overweight/obesity is more prevalent in urban than in rural settings of SSA [24]. In a study involving 1799 Nigerian adolescents aged between 10 and 19 years, the comparison of BMI between adolescents of rural and urban areas revealed higher BMI amongst the latter [86]. Similar data were reported in a nationwide study carried out in Cameroon, where urban children aged 6-59 months had a higher prevalence of overweight/obesity than their counterparts in rural settings $(8.7 \%$ vs. $7.6 \%)$ [87]. As stated previously, the reasons may stem from urbanisation of SSA cities and an economic transition which in turn has led to an increased sedentary behaviour and an easy access to packaged foods high in saturated fats and sugars, two major risks factors for obesity [24].

Pre-conception, maternal, and intrauterine factors There is limited data citing the impact of maternal pregestational and gestational BMI on body composition of off-spring in SSA. The few available studies highlight that overweight/obese mothers have a 1.07 to 2 fold increased risk of having an overweight/obese child [36, 60, 87, 88].

Maternal level of education has also been described as predictive of offspring overweight and obesity. Children whose mothers have primary education or no formal education have been reported in a meta-analysis to respectively have a 1.23 and 1.10 times increased odds of being overweight/obese [36], probably explained by the fact that less educated mothers may have poor knowledge on healthy diets or may perceive childhood overweight/obesity as healthy and desirable. In contrast, findings from a Kenyan study not included in this metaanalysis identified that primary, secondary and higher maternal levels of education were associated with higher odds of childhood overweight/obesity [88]. This could be explained by the fact that an educated mother is more likely to be employed and have a higher household income, which in turns may lead to increased affordability for high energy-dense foods. Likewise, the prevalence of childhood overweight/obesity in SSA has been reported to increase with decreasing maternal age [36].

Birth weight One systematic review [36] and two crosssectional studies $[87,88]$ have shown higher odds of overweight/obesity for SSA children born with the traditional cut-off value $\geq 4000 \mathrm{~g}$ for high birth weight (HBW) $(\geq 4000 \mathrm{~g})$ in SSA. However, using the standard recommended WHO definition for HBW (90th centile of birth weights), a more recent study conducted on almost 5000 neonates in a SSA setting, found $3850 \mathrm{~g}$ to be the actual cut-off of HBW [89]. Hence, the aforementioned studies [36, 87, 88] may have some methodological flaws in that they underestimated the true association between childhood overweight/obesity and HBW due to the fact that the exact 90th centile of birth weights was not considered.

Miscellaneous determinants Low birth order has also been associated with a lower risk of obesity and overweight in SSA [36]. This relationship may be secondary to the higher susceptibility of first order births to low birth weight, which in turn can result in lower weight during childhood [90]. Also, the association across religions has been reported in a nationwide Cameroonian study [87]. The Muslim religion was associated with a lower risk of childhood overweight and obesity compared to Christianity. According to the authors, the dietary habits can be influenced by the compliance to the rules of religion [87]. In addition, learning in a private school has been shown to increase the odds of overweight/obesity in Ethiopian [43, 46] and Burkinabe children and adolescents [39]. However, this risk is confounded by SES, given that students enrolled in private schools are usually of high SES which exposes them to more high caloric foods and passive means of transport to school compared to students attending government schools.

\section{Risk factors for the development of cardiovascular disease among overweight/obese children and adolescents}

Metabolic syndrome Paediatric metabolic syndrome is defined as the constellation of at least three of the following criteria: (i) fasting glucose $\geq 110 \mathrm{mg} / \mathrm{dl}$; (ii) high density lipoprotein cholesterol $\leq 50 \mathrm{mg} / \mathrm{dl}$ (except in boys aged 15 to 19 years in whom the cut point is $45 \mathrm{mg} / \mathrm{dl}$ ); (iii) fasting triglyceride $\geq 100 \mathrm{mg} / \mathrm{dl}$; (iv) systolic blood pressure $>$ 90th percentile for gender, age and height; (v) waist circumference $>75$ th percentile for age and gender [91]. Other more universally accepted definitions include 
that of the International Diabetes Foundation which defines paediatric metabolic syndrome as an association of at least two metabolic abnormalities (central obesity $\geq 9$ Oth percentile, high blood pressure $\geq 130 / 85 \mathrm{mmHg}$, hypertriglyceridemia $\geq 150 \mathrm{mg} / \mathrm{dl}$ or $1.7 \mathrm{mmol} / \mathrm{l}$, low high density lipoprotein cholesterol below $40 \mathrm{mg} / \mathrm{dl}$ or 1.03 $\mathrm{mmol} / \mathrm{l}$, impaired glucose tolerance with glycaemia $\geq 100 \mathrm{mg} / \mathrm{dl}$ or $5.6 \mathrm{mmol} / \mathrm{l}$ ) [92]. Obesity is the major trigger of this syndrome since it is well known that being overweight during childhood is associated with glucose intolerance, high levels of serum lipids and elevated blood pressure in young adulthood [37]. Insulin resistance, secondary to central adiposity has multiple metabolic consequences other than dysglycaemia has multiple metabolic consequences other than dysglycaemia including enhanced cholesterol synthesis, increased high-density lipoprotein (HDL) degradation, increased sympathetic activity and proliferation of vascular smooth muscle cells [93].

There is a parallel increase between the prevalence of metabolic syndrome and childhood overweight/obesity in SSA [94]. In a case-control study conducted on 1016 years old South African children and adolescents, the prevalence of metabolic syndrome in obese students was $13.2-30.2 \%$ depending on the definition used. Low HDL was the most common (48.3\%) component of paediatric metabolic syndrome whilst impaired fasting blood glucose the least frequent (5.6\%) [95]. In a recent crosssectional study conducted in Cameroon to compare the cardio-metabolic profile of obese children versus matched lean control subjects, the prevalence of metabolic syndrome was 19\% [96]. A higher prevalence of elevated blood pressure, dyslipidaemia and type 2 diabetes was found in obese children compared to lean counterparts [96].

Diabetes, insulin resistance, and glucose intolerance Data on glucose intolerance and type 2 diabetes in overweight/obese SSA children arescarce. In the aforementioned cohort of 38 obese Cameroonian children aged 3 to 17 years, only one child had type 2 diabetes [96]. However, $60 \%$ of these obese children had acanthosis nigricans, a marker of insulin resistance [96]. If not addressed, the prevalence of type 2 diabetes in this population will certainly increase. In a retrospective study to determine the prevalence of type 2 diabetes among 985 Sudanese children and adolescents, type 2 diabetes was found in $38(4 \%)$ children and adolescents who were all obese [97].

Hypertension There is also little data on the prevalence of hypertension in overweight/obese SSA children and adolescents. Hypertension was strongly associated with obesity in a study involving South African adolescent aged 13-
17 years [98]. The prevalence of hypertension (systolic and diastolic blood pressure $\geq 95$ th percentile for age, sex and height) and prehypertension (systolic or diastolic blood pressure $\geq 90$ thto $<95$ thpercentile for age sex and height) in obese adolescents was $32.6 \%$ in females and $32.8 \%$ in males [98]. Meanwhile, in Cameroon, the prevalence of hypertension in obese children was $25 \%$ [96] and $27.7 \%$ of obese Nigerian adolescents were hypertensive [99]. Furthermore, the prevalence of hypertension in overweight and obese Sudanese children was 17.8 and 31.2\% respectively [67]. Obese Sudanese children were 15 -fold more likely to have systolic hypertension than normal-weight counterparts [67].

Atherogenic dyslipidaemia, atherosclerosis and smoking We identified one study in Cameroon, which demonstrated that the prevalence of dyslipidaemia (high levels of total cholesterol, low-density lipoprotein (LDL) cholesterol and triglycerides) in obese children was 16\% [96]. There was a statistical significant difference in the medians of total cholesterol $(164.5$ vs. $115 \mathrm{mg} / \mathrm{dl})$ and LDL cholesterol (102.5 vs. $72 \mathrm{mg} / \mathrm{dl}$ ) between obese and lean Cameroonian children [96].

A study on Ghanaian and Ugandan adolescents aged 13-15 years demonstrated a positive association between overweight/obesity and smoking [73]. Here, smoking increased the odds of overweight/obesity by 1.75 and 1.52 in regular male and female adolescent smokers, respectively [73]. However, because the study used a crosssectional design, it was impossible to infer causality or untangle bi-directional relationships.

Overall, Fig. 2 illustrates the interaction between childhood and adolescence obesity or overweight and cardiovascular risk factors in sub-Saharan Africa 11.

\section{Management of childhood and adolescence overweight/ obesity}

Currently, there have been no clinical trials performed in SSA to ascertain which treatments may be best suited for preventing or reducing childhood and adolescence overweight/obesity and its associated cardiovascular risk factors. However, it is also true that interventions from mainly high-income settings comparing that combined behavioural interventions (physical activity, dietary therapy) to standard or no care can yield a statistically significant but probably clinically insignificant reduction in body mass indices in children and adolescents [100-102].

Strategies for overweight/obesity prevention and treatment in children and adolescents should be implemented holistically in natural settings in order to impact on diet and physical activities in preschool, schools, after-school care services and at homes. The management of childhood and adolescence overweight/obesity 


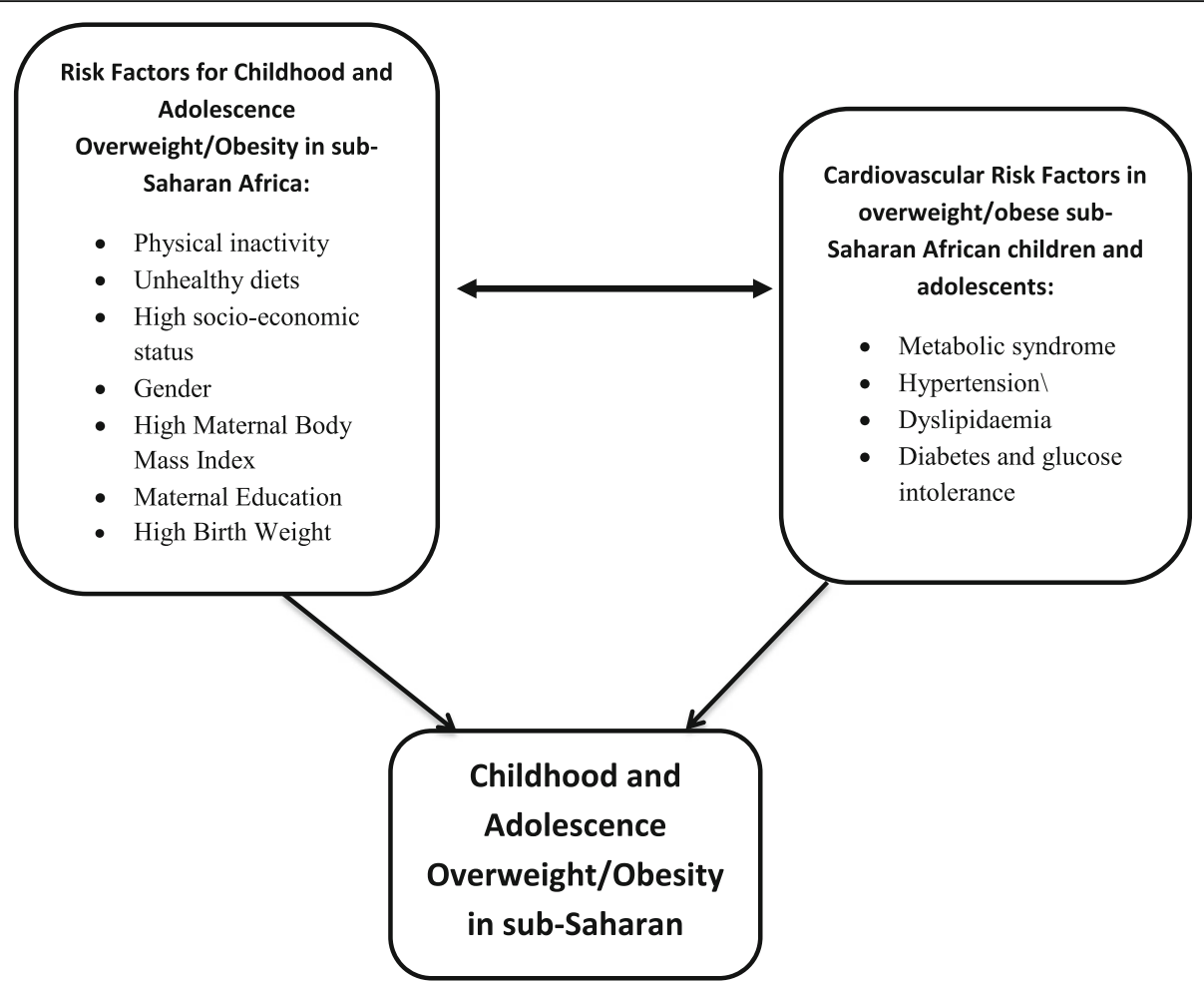

Fig. 2 The interaction between childhood and adolescence obesity or overweight and cardiovascular risk factors in sub-Saharan Africa

requires a multi-sectoral public health approach that focuses on transforming the current obesogenic environment of the child into one which promotes physical activity, healthy diet and the early recognition of excessive weight gain relative to linear growth [103, 104].

\section{Physical activity}

Although there is no high-quality study investigating the impact of physical activity on overweight/obese children and adolescents with cardiovascular risk factors in SSA, guidelines from similar resource-limited settings recommend that overweight/obese children and adolescents should engage in at least 45-60 min of moderate intensity physical activity (either sports or bicycling) most days of the week [105]. Meanwhile, WHO guidelines stipulate that obese children and adolescents aged between 5 and 17 years old should carry out a minimum of $60 \mathrm{~min}$ of moderate-to-vigorous intensity physical activity at least three times per week [106]. This measure yields fundamental health benefits such as increased cardiorespiratory fitness, muscular strength, reduced body fat, enhanced bone health, favourable metabolic biomarkers, and reduced symptoms of anxiety and depression [106]. Physical activities should preferably be aerobic and sessions of more than 60 min duration have been shown to provide additional health benefits [106]. The type of physical activity ought to be individualised according to the preference and interest of the child, culture, and local practices. For instance, aerobic dance with popular music may appeal more to girls, whereas boys may enjoy more vigorous outdoor sport and martial arts. The involvement of parents is equally pivotal in determining the success rate of the chosen physical activity $[107,108]$.

\section{Healthy diets}

Public health interventions to tackle childhood and adolescence overweight/obesity in SSA through healthy eating are few. Currently, only South Africa has school-based interventions to promote healthy eating habits in overweight/obese primary-school children, with a main focus on children from low socio-economic status $[109,110]$. These public health programs have modules on physical activity, complications of cigarette smoking and chronic diseases (especially type 2 diabetes). Here, the adherence of children is enhanced through the concomitant involvement of teachers and parents in all modules $[109,110]$. Furthermore, it is important to limit the availability of high energy density fast foods (chocolates, candies, ice creams, patties, potatoes or plantain chips) and carbonated beverages in school refectories while simultaneously providing healthier options for children [79].

Strategies to curb the burden of childhood and adolescence overweight/obesity through eating behaviours could 
be extended to homes because children and adolescents partaking in regular family meals are more likely to eat vegetable- and fruit-based diets and less likely to consume unhealthy foods [111]. Unlike non-vegetarians, vegetarian children and adolescents are usually of normal BMI and this BMI advantage increases during adolescence [112]. This is probably because vegetable-based diets are of lowcaloric density, but high in complex carbohydrate, fibre and water, which consequently increase satiety and resting energy expenditure. Also, healthy cooking methods entailing boiling, steaming, roasting, and baking should be adopted by parents/guardians of children and adolescents. Finally, the ideal way for parents to encourage healthy eating habits in children is by setting an example. Parents should share at least one meal with children, preferably a balanced diet. They should themselves have smaller portions, fruits, and vegetables whilst discouraging overeating in their children [79].

\section{Conclusion}

This review examined the problems associated with childhood and adolescence overweight/obesity and cardiovascular risk factors in SSA. These may be resolved if the following recommendations are put in place. Firstly, we need to establish a more robust clinical method to assess childhood and adolescence overweight/obesity in SSA through the universal adoption of the WHO cut-off points. This possibly should be accompanied by a basic screening of cardiovascular risk factors in children and adolescents found overweight or obese: blood pressure, basic lipid profiles and where age appropriate smoking history. Secondly, there is urgent need to decrease the high prevalence of childhood and adolescence overweight/obesity; accordingly, health promotion activities need to be instituted in SSA through health education of parents/guardians, children and adolescents on the ill-health of childhood and adolescence overweight/obesity. Thirdly, there is the need to revamp the current educational system in SSA countries through the incorporation of a compulsory module on physical activity and healthy diets in schools. Furthermore, the involvement of parents/guardians in these interventions will be important to enhance children's adherence. In addition, state taxation on energy dense food and sugary drinks and a ban on the advertisement of high energy dense foods like fast foods, sweet foods, and beverages by food industries will decrease the number of SSA children and adolescents purchasing or having access to these products. Finally, SSA ministries of health should work in collaboration with ministries of education to ensure cost-effective implementation of these public health interventions. Overall, these policies will go a long way to build sustainable health and educational systems that could help in reducing the burden associated with this condition in SSA.

\section{Abbreviations}

BMI: Body mass index; CDC: Centres for Disease Control and Prevention; CVD: Cardiovascular disease; CVRF: Cardiovascular risk factor; HDL: Highdensity lipoprotein; IOTF: International Obesity Task Force; LDL: Low-density lipoprotein; NCD: Non-communicable disease; SES: Socio-economic status; SSA: sub-Saharan Africa; UN: United Nations; WHO: World Health Organisation

\section{Acknowledgments}

JPHS is funded by the National Institute for Health Research (NIHR) within the Bristol Biomedical Research Centre (Nutrition Theme) at University Hospitals Bristol NHS Foundation Trust and The University of Bristol. 14.

\section{Authors' contributions}

SPC, JNT and ATS conceived and designed the study, run the preliminary search. SPC, JNT, ATS and JRN independently selected studies, extracted data from selected studies and assess the methodology of all included study. SPC, JNT and ATS wrote the first draft of the manuscript, subsequently reviewed and revised by ATS, JNT, JRN, SPC and JPHS. All authors approved the final manuscript. SPC is the guarantor for this study.

Funding

Not applicable.

Availability of data and materials

All data generated or analysed during this study are included in this published article.

\section{Ethics approval and consent to participate}

This article is a review; consequently, there is no ethical statement required.

\section{Consent for publication}

Not applicable.

\section{Competing interests}

The authors declare that they have no competing interests.

\section{Author details}

${ }^{1}$ Department of Clinical Sciences, Faculty of Medicine and Pharmaceutical Sciences, University of Dschang, Dschang, Cameroon. ${ }^{2}$ Health and Human Development (2HD) Research Network, Douala, Cameroon. ${ }^{3}$ Diabetes and Endocrine Unit, Department of Internal Medicine, Douala General Hospital, Douala, Cameroon. ${ }^{4}$ Department of Anesthesiology and Critical Care Medicine, Faculty of Medicine and Biomedical Sciences, University of Yaoundé I, Yaoundé, Cameroon. ${ }^{5}$ Department of Pediatrics, Faculty of Medicine and Biomedical Sciences, University of Yaoundé I, Yaoundé, Cameroon. ${ }^{6}$ Disease, Epidemics and Pandemics Control, Ministry of Public Health, Yaoundé, Cameroon. ${ }^{7}$ Bristol Biomedical Research Centre (Nutrition Theme), University of Bristol and University Hospitals Bristol NHS Foundation Trust, Bristol, UK.

Received: 28 August 2019 Accepted: 13 February 2020

Published online: 24 March 2020

\section{References}

1. WHO. World Health Statistics. 2017 Available from http://apps.who.int/iris/ bitstream/10665/255336/1/9789241565486-eng.pdf. Accessed 17 June 2019.

2. Van der Sande MAB, Ceesay SM, Milligan PJM, Nyan OA, Banya WAS, Prentice A, McAdam KPWJ, and Walraven GEL. Obesity and undernutrition and cardiovascular risk factors in rural and urban Gambian communities. Am J Public Health 2001;91(10): 1641-1644.

3. Popkin B. Dynamics of the nutrition transition and its implications for the developing world. Forum Nutr. 2003;56:262-4.

4. Duda R, Jumah N, Hill A, Steffah J, Birtwum R. Assessment of the ideal body image of women in Accra. Ghana Trop Doct. 2007;37(4):241-4.

5. Steyn K, Damasceno A. Lifestyle and related risk factors for chronic diseases. In: Jamison DT, Feachem RG, Makgoba MW, et al., editors. Disease and mortality in Sub-Saharan Africa. 2nd edition [mongraph on the internet]. Washington, DC: World Bank. 2006 [cited 2017 May 10]. http://www.ncbi. nlm.nih.gov/books/NBK2290/. 
6. Holdsworth M, Gartner A, Landais E, Maire B, Delpeuch F. Perceptions of healthy and desirable body size in urban Senegalese women. Int J Obes. 2004;28(12):1561-8.

7. Ng M, Fleming T, Robinson M, Thomson B, Graetz N, Margono C, et al. Global, regional, and national prevalence of overweight and obesity in children and adults during 1980-2013: a systematic analysis for the global burden of disease study 2013. Lancet. 2014;384:766-81.

8. Wang Y, Lobstein T. Worldwide trends in childhood overweight and obesity. Int J Pediatr Obes. 2006;1:11-25

9. de Onis M, Blossner M, Borghi E. Global prevalence and trends of overweight and obesity among preschool children. Am J Clin Nutr. 2010;92(5):1257-64

10. Rooney BL, Mathiason MA, Schauberger CW. Predictors of obesity in childhood, adolescence, and adulthood in a birth cohort. Matern Child Health J. 2010;15(8):1166-75

11. Fung C, Kuhle S, Lu C, Purcell M, Schwartz M, Storey K, et al. From « best practice » to « next practice »: the effectiveness of school-based health promotion in improving healthy eating and physical activity and preventing childhood obesity. Int J Behav Nutr Phys Act. 2012;9:27.

12. Reilly J, Kelly J. Long-term impact of overweight and obesity in childhood and adolescence on morbidity and premature mortality in adulthood: systematic review. Int J Obes. 2011;35:891-8.

13. Lawlor D, Benfield L, Logue J, Tilling K, Howe L, Fraser A, et al. Association between general and central adiposity in childhood, and change in these, with cardiovascular risk factors in adolescence: prospective cohort study. BMJ. 2010;341:c6224

14. The NS, Suchindran C, North KE, Popkin BM, Gordon-Larsen P. Association of adolescent obesity with risk of severe obesity in adulthood. JAMA. 2010;304: 2024-7 15.

15. Cowan P, Velasquez-Mieyer P, Christensen M, Perez-Faustinelli S. Cardiovascular risk factors increase with obesity severity in African American youth with and without type 2 diabetes (T2DM). Am J Med Sci. 2006;331(2):61-2.

16. Freedman DS, Dietz W, Srinivasan SR, Berenson GS. The relation of overweight to cardiovascular risk factors among children and adolescents: the Bogalusa heart study. Pediatrics. 1999;103:1175-82.

17. Berenson GS, Srinivasan SR, Bao W, Newman WP III, Tracy RE, Wattigney WA. Association between multiple cardiovascular risk factors and atherosclerosis in children and young adults. The Bogulasa heart study. N Engl J Med. 1998; 338:1650-6.

18. Berenson GS, Srinivasan SR, Wattigney WA, Harsha DW. Obesity and cardiovascular risk in children. Ann N Y Acad Sci. 1993;699:93-103.

19. Berenson GS, Wattigney WA, Tracy RE, Newman 3rd WP, Srinivasan SR, Webber LS, Dalferes ER, Strong SP. Atherosclerosis of the aorta and coronary-arteries and cardiovascular risk-factors in persons aged 6 to 30 years and studied at necropsy (the Bogalusa heart study). Am J Cardiol 1992;70:851-858.

20. Maggisano V, Chiaroti F, Botunac I, Campanella C, Gallietta G, Loizzo A. Adolescence as possible critical window for blood pressure short term monitoring in boys and girls. Eur J Epidemiol. 2005;20:517-24.

21. Hoy D, Brooks P, Woolf A, Blyth F, March L, Bain C, et al. Assessing risk of bias in prevalence studies: modification of an existing tool and evidence of interrater agreement. J Clin Epidemiol. 2012;65:934-9.

22. Chan A-W, Tetzlaff JM, Altman DG, Laupacis A, Gotzsche PC, Krleza-Jeric K et al. SPIRIT 2013 Statement:Defining Standard Protocol Items for Clinical trials. Ann InternalMed 2013;1-w-2.

23. Shea BJ, Reeves BC, Wells G, Thuku M, Hamel C, Morn J, et al. AMSTAR 2: acriticalappraisaltolol for systematicreviewsthatincluderandomised and nonrandomisedstudies of healthcare interventions, or both. BMJ. 2017;358:j4008.

24. Muthuri SK, Francis CE, Wachira L-JM, LeBlanc AG, Sampson M, Onywera VO, et al. Evidence of an overweight/obesity transition among school-aged children and youth in sub-Saharan Africa: a systematic review. PLoS One. 2014;9(3):e92846.

25. Field AE, Laird N, Steinberg E, Fallon E, Semega-Janneh M, Yanovski JA. Which metric of relative weight best captures body fatness in children? Obes Res. 2003;11(11):1345-52.

26. Mei Z, Grummer-Strawn LM, Pietrobelli A, Goulding A, Goran MI, Dietz WH. Validity of body mass index compared with other body-composition screening indexes for the assessment of body fatness in children and adolescents. Am J Clin Nutr. 2002;75(6):978-85.

27. Flegal KM, Ogden CL, Yanovski JA, Freedman DS, Shepherd JA, Graubard Bl, et al. High adiposity and high body mass index-for-age in US children and adolescents overall and by race-ethnic group. Am J Clin Nutr. 2010;91(4):1020-6.
28. Wellens RI, Roche AF, Khamis HJ, Jackson AS, Pollock ML, Siervogel RM. Relationships between the Body Mass Index and body composition. Obes Res. 1996;4(1):35-44 16.

29. Neovius M, Linné Y, Rossner S. BMI, waist-circumference and waist-hip-ratio as diagnostic tests for fatness in adolescents. Int J Obes. 2004;29(2):163-9.

30. WHO [homepage on the Internet] Child growth standard 2006 [cited 2017 May 20]. Available from: http://www.who.int/childgrowth.

31. Butte NF, Garza C, de Onis M. Evaluation of the feasibility of international growth standards for school-aged children and adolescents. J Nutr. 2007; 137:153-7.

32. Kuczmarski RJ, Ogden CL, Grummer-Strawn LM, Flegal KM, Guo SS, Wei R, Mei Z, Curtin LR, Roche AF, Johnson CL. CDC growth charts: United States. Adv Data. 2000:314:1-27.

33. Cole TJ, Bellizzi MC, Flegal KM, Dietz WH. Establishing a standard definition for child overweight and obesity worldwide: international survey. BMJ. 2000; 320:1240-3

34. Unwin N, Setel P, Rashid S, Mugusi F, Mbanya J, Kitange H, et al. Noncommunicable diseases in sub-Saharan Africa: where do they feature in the health research agenda? Bull World Health Organ. 2001;79:947-53.

35. Shields M. Overweight Canadian children and adolescents. Health Rep. 2005;17:27-42.

36. Gebremedhin S. Prevalence and differentials of overweight and obesity in preschool children in SubSaharan Africa. BMJ Open. 2015;5:e009005.

37. UNICEF, WHO, World Bank Group. Joint child malnutrition estimates - Levels and trends in child malnutrition. 2017 [cited 2017 May 23]. Available from: http://www.who.int/nutgrowthdb/estimates2016/en/.

38. Manyanga T, El-Sayed H, Doku DT, Randal JR. The prevalence of underweight, overweight, obesity and associated risk factors among school-going adolescents in seven African countries. BMC Public Health. 2014;14:887.

39. Dabone C, Delisle HF, Receveur O. Poor nutritional status of schoolchildren in urban and peri -urban areas of Ouagadougou (Burkina Faso). Nutr J. 2011;10:34.

40. Kouéta F, Dao L, Dao F, Djekompté S, Sawadogo J, Diarra Y, Kam KL, Sawadogo A. Facteurs associés au surpoids et à l'obésité des élèves de Ouagadougou (Burkina Faso). Sante. 2011;21:227-31.

41. Choukem SP, Kamdeu-Chedeu J, Leary SD, Mboue-Djieka Y, Nebongo DN, Akazong $C$, et al. Overweight and obesity in children aged 3-13 years in urban Cameroon: a crosssectional study of prevalence and association with socio-economic status. BMC Obesity. 2017:4:7.

42. Teshome T, Singh P, Moges D. Prevalence and associated factors of overweight and obesity among high school adolescents in urban communities of Hawassa, southern Ethiopia. Curr Res Nutr Food Sci J. 2013;1(1):23-36.

43. Alemu E, Atnafu A, Yitayal M, Yimam K. Prevalence of Overweight and/or Obesity and Associated Factors among High School Adolescents in Arada Sub city, Addis Ababa, Ethiopia. J Nutr Food Sci. 2014;4:261 17.

44. Askal T, Yifokr T, Bekri M, Getachew TG. Prevalence and associated factors of overweight and/or obesity among primary school children in bole Sub-City, Addis Ababa, Ethiopia. J Nutr Food Sci. 2015:5:5.

45. Gebremichael B, Chere A. Prevalence of childhood overweight and obesity and its determinant factors among elementary school children in Addis Ababa, Ethiopia: A Cross Sectional Study. J Nutr Disord Ther. 2015;S1:002.

46. Shegaze $M$, Wondafrash M, Alemayehu AA, Mohammed S, Shewangezaw Z, Abdo M, Gendisha G. Magnitude and determinants of overweight and obesity among high school adolescents in Addis Ababa, Ethiopia. Int J Med Health, Biomed Bioeng Pharmaceutical Eng. 2016;10(4):215-21.

47. Desalew CA, Mandesh A, Semahegn A. Childhood overweight, obesity and associated factors among primary school children in Dire Dawa, eastern Ethiopia; a cross-sectional study. BMC Obes. 2017:4:20.

48. Kyallo F, Makokha A, Mwangi M. Overweight and obesity among public and private primary school children in Nairobi, Kenya. Health. 2013;5: 85-90.

49. Morge V, Gaa PK, Abukari RNS. Overweight, obesity and thinness and associated factors among school-aged children (5-14 years) in Tamale, Northern Ghana. Eur Scientific J. 2013;9(20):160-75

50. Kumah DB, Akuffo KO, Abaka-Cann JE, Affram DE, Osae EA. Prevalence of Overweight and Obesity among Students in the Kumasi Metropolis. J Nutrition Metabolism 2015;2015, Article ID 613207, 4 pages, doi:https://doi. org/10.1155/2015/613207.

51. Mohammed H, Vuvor F. Prevalence of childhood overweight/obesity in basic School in Accra. Ghana Med J. 2012;46(3):124-7. 
52. Kramoh KE, N'goran YNK, Aké-Traboulsi E, Boka BC, Harding DE, Koffi DBJ, et al. Prévalence de l'obésité en milieu scolaire en Côte d'Ivoire. Ann Cardiol Angéiologie. 2012;61(3):145-9.

53. Kamau J, Wanderi M, Njororai W, Wamukoya E. Prevalence of overweight and obesity among primary school children in Nairobi province, Kenya. Afr J Physical Activity Health Sci. 2011;17(2):67668.

54. Van den Berg VL, Seheri L, Raubenheimer J. Body mass index of 16year olds in urban Maseru, Lesotho. Afr J Prim Health Care Fam Med. 2014;6(1):618

55. Oumar H, Menta I, Camara Y, Sangaré I, Sidibé N, Doumbia S, Diarra MB. Surpoids et obésité dans la population au-dessus de 20 ans en milieu urbain bamakois (Mali). Pan Afr Med J. 2014;19:351.

56. Caleyachetty R, Rudnicka AR, Echouffo-Tcheugui JB, Siegel KR, Richards N, Whincup PH. Prevalence of overweight, obesity and thinness in 9-10 year old children in Mauritius. Glob Health. 2012;8:28.

57. Ejike C. Child and adolescent obesity in nigeria: A narrative review of prevalence data from three decades (1983-2013). J Obes Metab Res. 2014;1(3):174 18.

58. Adam V, Isah J. Prevalence and comorbidities of childhood overweight and obesity among school aged children in an urban settlement in Benin City. Nigeria Niger J Paediatr. 2017:44(1):7.

59. Faye J, Diop M, Gati Ouonkoye R, Seck M, Mandengué S, Mbengue A, et al. Prévalence de l'obésité de l'enfant et de l'adolescent en milieu scolaire à Dakar. Bull Société Pathol Exot. 2011;104(1):49-52.

60. Stettler $N$, Bovet $P$, Shamlaye $H$, Zemel BS, Stallings VA, Paccaud $F$. Prevalence and risk factors for overweight and obesity in children from Seychelles, a country in rapid transition: the importance of early growth. Int J Obes Relat Metab Disord. 2002;26(2):214-9.

61. Armstrong MEG, Lambert MI, Sharwood KA, Lambert EV. Obesity and overweight in south African primary school children - the health of the nation study. S Afr Med J. 2006;96:439-44.

62. Toriola AL, Moselakgomo VK, Shaw BS, Goon DT. Overweight, obesity and underweight in rural black south African children. S Afr J Clin Nutr. 2012; 25(2):57-61.

63. Tathiah N, Moodley I, Mubaiwa V, Denny L, Taylor M. Overweight, obesity, underweight and stunting in female primary school learners in rural KwaZulu-Natal, South Africa. S Afr Med J. 2013;103(10):718.

64. Pienaar AE. Prevalence of overweight and obesity among primary school children in a developing country: NW-CHILD longitudinal data of 6-9-yr-old children in South Africa. BMC Obesity. 2015;2:2.

65. Aisha AMB, Hoyem AA, Tagwa ME, Samia AS. Prevalence of obesity and overweight among the female students in basic school levels in Omdurman- Sudan. Sud Med Lab J. 2011;1(2):20-5.

66. Nagwa MA, Elhussein AM, Azza M, Abdulhadi NH. Alarming high prevalence of overweight/obesity among Sudanese children. Eur J Clin Nutr. 2011;65(3):409-11.

67. Salman Z, Kirk GD, DeBoer MD. High rate of obesity-associated hypertension among primary schoolchildren in Sudan. Int J Hypertens. 2011;2011:629492.

68. El Raghi HA, Abdel-Aziz SB, Shalaby SF, El-Khider RK. Prevalence of obesity in mentally disabled children attending special special education Institutes in Khartoum State. J Childhood Obesity. 2016;1:1-8.

69. Pangani IN, Kiplamai FK, Kamau JW, Onywera VO. Prevalence of overweight and obesity among primary school children aged $8 ? 13$ years in Dar es Salaam City, Tanzania. Adv Prev Med. 2016;2016:1-5.

70. Kimario JT. Prevalence of obesity and overweight among school children in Moshi municipality, Kilimanjaro, Tanzania. Master's dissertation. Ghent University; 2015. [cited 2017 May 25]. Available from http://lib.ugent.be/ fulltxt/RUG01/002/217/238/RUG01-002217238_2015_0001_AC.pdf.

71. Chebet M, Nsibambi C, Otala J, Goon DT. Prevalence of overweight and obesity among primary school children in Kampala central, Uganda. Afr J Physical Health Education, Recreation Dance. 2014;20(4):1365-78 19.

72. Nsibambi CAN. Body composition analysis of pupils in urban schools in Central Uganda. Int J Bus Soc Sci. 2013;4(7):135-41.

73. Peltzer K, Pengpid S. Overweight and obesity and associated factors among school-aged adolescents in Ghana and Uganda. Int J Environ Res Public Health. 2011;8(12):3859-70.

74. Ogden CL, Carroll MD, Kit BK, Flegal KM. Prevalence of obesity and trends in body mass index among US children and adolescents, 1999-2010. JAMA. 2012;307:483-90.

75. Tremblay M, Katzmarzyk P, Willms J. Temporal trends in overweight and obesity in Canada, 1981-1996. Int J Obes Relat Metab Disord. 2002;26: 538-43.
76. Nyawornota V, Aryeetey R, Bosomprah S, Aikins M. An exploratory study of physical activity and over-weight in two senior high schools in the Accra Metropolis. Ghana Med J. 2013;47(4):197-203.

77. Tremblay MS, LeBlanc AG, Kho ME, Saunders TJ, Larouche R, Colley RC, et al. Systematic review of sedentary behaviour and health indicators in schoolaged children and youth. Int J Behav Nutr Phys Act. 2011;8:98.

78. Popkin BM. The nutrition transition and obesity in the developing world. J Nutr. 2001;131:871S-3S.

79. Guptha N, Goel K, Shah P, Mishra A. Childhood obesity in developing countries: epidemiology, determinants, and prevention. Endocr Rev. 2012;33:48-70.

80. Misra A, Khurana L. Obesity and the metabolic syndrome in developing countries. J Clin Endocrinol Metab. 2008;93:S9-S30.

81. Story M, Hayes M, Kalina B. Availability of foods in high schools: is there cause for concern? J Acad Nutr Diet. 1996;96(2):123.

82. Ebbeling CB, Pawlak DB, Ludwig DS. Childhood obesity: public-health crisis, common sense cure. Lancet Lond Engl. 2002;360(9331):473-82.

83. Feeley A, Musenge E, Pettifor JM, Norris SA. Changes in dietary habits and eating practices in adolescents living in urban South Africa: the birth to twenty cohort. Nutr Burbank Los Angel Cty Calif. 2012;28(7-8):e1-6.

84. Dinsa GD, Goryakin Y, Fumagalli E, Suhrcke M. Obesity and socioeconomic status in developing countries: a systematic review. Obes Rev Off J Int Assoc Study Obes. 2012;13(11):1067-79.

85. Fruhstorfer $\mathrm{BH}$, Mousoulis C, Uthman OA, Robertson W. Socio-economic status and overweight or obesity among school-age children in subSaharan Africa - a systematic review. Clin Obes. 2016;6(1):19-32.

86. Omigbodun $\mathrm{OO}$, Adediran Kl, Akinyemi JO, Omigbodun AO, Adedokun BO, Esan O. Gender and rural-urban differences in the nutritional status of in-school adolescents in South-Western Nigeria. J Biosoc Sci. 2010; 42(5):653-76.

87. Tchoubi S, Sobngwi-Tambekou J, Noubiap JJN, Asangbeh SL, Nkoum BA, Sobngwi E. Prevalence and risk factors of overweight and obesity among children aged 6-59 months in Cameroon: 20 a multistage, stratified cluster sampling Nationwide survey. PLoS One. 2015;10(12):e0143215.

88. Gewa CA. Childhood overweight and obesity among Kenyan pre-school children: association with maternal and early child nutritional factors. Public Health Nutr. 2010;13(4):496-503.

89. Choukem S-P, Njim T, Atashili J, Hamilton-Shield JP, Mbu R. High birth weight in a suburban hospital in Cameroon: an analysis of the clinical cut-off, prevalence, predictors and adverse outcomes. BMJ Open. 2016;6(6):e011517.

90. Kodzi IA, Kravdal $\varnothing$. What has high fertility got to do with the low birth weight problem in Africa? Demogr Res. 2013;28:713-32.

91. de Ferranti SD, Gauvreau K, Ludwig DS, Neufeld EJ, Newburger JW, Rifai N. Prevalence of the metabolic syndrome in American adolescents: findings from the third National Health and nutrition examination survey. Circulation. 2004;110:2494-7.

92. Zimmet $P$, Alberti $K$, George MM, Kaufman F, Tajima N, Silink M. The metabolic syndrome in children and adolescents - an IDF consensus report. Pediatr Diabetes. 2007:8:299-306.

93. Daniels SR, Arnett DK, Eckel RH, Gidding SS, Hayman LL, Kumanyika S, et al. Overweight in children and adolescents: pathophysiology, consequences, prevention, and treatment. Circulation. 2005;111:1999-2012.

94. Kelishadi R. Childhood overweight, obesity, and the metabolic syndrome in developing countries. Epidemiol Rev. 2007;29:62-76.

95. Matsha T, Hassan S, Bhata A, Yako Y, Fanampe B, Somers A, et al. Metabolic syndrome in 10-16-year-old learners from the Western cape, South Africa: comparison of the NCEP ATP III and IDF criteria. Atherosclerosis. 2009;205(2):363-6.

96. Chedjou-Nono E, Sap S, Choukem SP, Ngosso Tetanye I, Nebongo D, Koki NO. Cardiometabolic profile of obese children in a sub-Saharan African setting: a cross-sectional study. BMC Pediatr. 2017;17:129.

97. Osman HAM, Elsadek N, Abdullah MA. Type 2 diabetes in Sudanese children and adolescents. Sudan J Paediatr. 2013;13(2):17-23.

98. Sekokotla MA, Goswami N, Sewani-Rusike CR, Iputo JE, Nkeh-Chungag BN. Prevalence of metabolic syndrome in adolescents living in Mthatha, South Africa. Ther Clin Risk Manag. 2017;13:131-7.

99. Oduwole AA, Ladapo TA, Fajolu IB, Ekure EN, Adeniyi OF. Obesity and elevated blood pressure among adolescents in Lagos, Nigeria: a crosssectional study. BMC Public Health. 2012;12(1):616.

100. Birch L, Perry R, Hunt LP, Matson RIB, Chong A, Beynon R, Hamilton-Shield J. What change in body mass index is associated with improvement in 
percentage body fat in childhood obesity? A meta-regression. BMJ Open. 2019; https://doi.org/10.1136/bmjopen-2018-028231.

101. Oude Luttikhuis H, Baur L, Jansen H, Shrewsbury VA, O'Malley C, Stolk RP, Summerbell CD. Interventions for treating obesity in children. Cochrane Database Syst Rev. 2009;1:CD001872 21.

102. Ford AL, Hunt LP, Cooper A, Shield JP. What reduction in BMI SDS is required in obese adolescents to improve body composition and cardiometabolic health? Arch Dis Child. 2010;95(4):256-61.

103. WHO. Global strategy on diet, physical activity and health. Geneva: WHO; 2004.

104. WHO. Resolution WHA65.6. WHO comprehensive implementation plan on maternal, infant, and young child nutrition. Maternal, infant and young child nutrition. In: Sixty-fifth World Health Assembly, Geneva, 21-26 May. Resolutions and decisions annexes. Geneva: WHO; 2012.

105. Misra A, Chowbey P, Makkar BM, Vikram NK, Wasir JS, Chadha D, Joshi SR, Sadikot S, Gupta R, Gulati S, Munjal YP. Consensus statement for diagnosis of obesity, abdominal obesity and the metabolic syndrome for Asian Indians and recommendations for physical activity, medical and surgical management. J Assoc Physicians India. 2009;57:163-70.

106. WHO. Global recommendations on physical activity for health. Geneva: WHO; 2010.

107. Murnan J, Price JH, Telljohann SK, Dake JA, Boardley D. Parents' perceptions of curricular issues affecting children's weight in elementary schools. J Sch Health. 2006;76:502-11.

108. Fogelholm M, Nuutinen O, Pasanen M, Myohanen E, Saatela T. Parent-child relationship of physical activity patterns and obesity. Int J Obes Relat Metab Disord. 1999;23:1262-8.

109. Draper CE, de Villiers A, Lambert EV, Fourie J, Hill J, Dalais L, Abrahams Z, Steyn NP. Study protocol HealthKick: a nutrition and physical activity intervention for primary schools in low-income settings. BMC Public Health. 2010;10:398.

110. Anonymous 2008 [monograph on the internet cited 2017 May 13]. http:// www.world-heart-federation.org/fileadmin/user_upload/images/members area/Workshops/2009_June_healthy_lifestyles_for_Children_Geneva/ initial\%20report\%20on\%20children\%20programmes\%202008.pdf. World Heart Federation.

111. Nemours Kids Health from Nemours. Healthy Eating 2009[cited 2017 May 25]. http://kidshealth.org/parent/nutrition_fit/nutrition/habits.html.

112. Key TJ, Fraser GE, Thorogood M, Appleby PN, Beral V, Reeves G, Burr ML, Chang-Claude J, Frentzel-Beyme R, Kuzma JW, Mann J, McPherson K. Mortality in vegetarians and non-vegetarians: a collaborative analysis of 8300 deaths among 76,000 men and women in five prospective studies. Public Health Nutr. 1998;1:33-41.

\section{Publisher's Note}

Springer Nature remains neutral with regard to jurisdictional claims in published maps and institutional affiliations.

Ready to submit your research? Choose BMC and benefit from:

- fast, convenient online submission

- thorough peer review by experienced researchers in your field

- rapid publication on acceptance

- support for research data, including large and complex data types

- gold Open Access which fosters wider collaboration and increased citations

- maximum visibility for your research: over $100 \mathrm{M}$ website views per year

At BMC, research is always in progress.

Learn more biomedcentral.com/submissions 